\title{
Overview of Communication Network Switches Technology Development in Smart Substations
}

\author{
Yongkang Zheng ${ }^{1}$, Xiliu Tan ${ }^{1,2, *}$, Dewen Wang ${ }^{2}$, Lei Shi ${ }^{3}$, Zhiyong Chen ${ }^{3}$ and Wenbing $\mathrm{He}^{3}$ \\ ${ }^{1}$ State Grid Sichuan Electric Power Research Institute, Chengdu, China \\ ${ }^{2}$ North China Electric Power University, Baoding, China \\ ${ }^{3}$ Ganzi Power Supply Company, State Grid Sichuan Province Electric Power Company, Ganzi, China \\ ${ }^{*}$ Corresponding author
}

\begin{abstract}
As an important component of the smart grid, smart substations adopt the optical fiber as the main feature to replace the traditional cable communication network. Therefore, it is very important to research the key equipment switch technology of the smart substation network. This article first compares and summarizes the technical specifications and Changes in standards of switches in smart substations and the technical characteristics of each stage. Secondly, the latest performance requirements of the switch are analyzed. Then from the perspective of function realization, we discussed the key technologies that support the development of switches. Finally, the key research points and research prospects of smart substation network switch technology are summarized and prospected.
\end{abstract}

Keywords-smart substation; switch technology; function implementation; performance requirements

\section{INTRODUCTION}

As a development trend of substation automation technology, smart substations play an important role in the smart grid. Networking of communication systems is an important feature of intelligent substation automation systems, and it is also the basis for the progress of substation technology and various advanced application functions [1]. As the key equipment in a smart substation, the ability of the switch to work properly is crucial to the security and reliability of the smart substation and even the entire smart grid. With the advancement of smart substation construction, smart substation network switches also have new application requirements. To strengthen the standardization of intelligent substation network switches as the main means, and to improve the substation operation safety, intelligence, ease of operation and maintenance, and support for the control of the main station as the fundamental goal, unified appearance interface, information model, communication services, and standard parameter configuration , Application functions, version management, and quality control, complete the standardization of intelligent substation network switches, and ensure the safe and stable operation of the power grid. This article first compares and summarizes the technical specifications and Changes in standards of switches in smart substations and the technical characteristics of each stage. Secondly, the latest performance requirements of the switch are analyzed. Then from the perspective of function realization, we discussed the key technologies that support the development of switches. Finally, the key research points and research prospects of smart substation network switch technology are summarized and prospected. The direction of the development of smart substation switch technology is clarified.

\section{SMART SUBSTATION SWITCH TECHNOLOGY STANDARDS AND FEATURES}

This article is mainly based on the specifications of the switch to classify, combined with the smart substation update standards and network trends, the intelligent substation network switches are summarized in three stages, compared with the literature [2] based on the site construction situation is more authoritative. On the basis of commercial switches, the firstgeneration intelligent substation network switch technology adopts industrial-level design and components, increasing reliability requirements [3]. The second-generation intelligent substation network switch technology refers to the specification of the switch that describes certain specific conditions (such as parameters) on the first-generation technology [4]. The thirdgeneration intelligent substation network switch technology refers to the second-generation technology to comprehensively describe the switch specifications that respond to the latest technology and environmental changes to adjust the details [5].

\section{A. Generation 1 Smart Substation Switch Technical Specifications}

According to the requirements in the standard [3], standardize the switch environment, indicators, performance, installation, and technical services. Such as the application environment, the corresponding specifications are: ambient temperature, altitude, maximum relative humidity, maximum daily temperature difference, atmospheric pressure, seismic capacity.

The main technical specifications of the corresponding specifications are: power supply, insulation performance, heat and humidity resistance, anti-jamming performance, radio disturbance limits, structural appearance and so on.

The main performance requirements corresponding specifications are: general technical requirements, basic performance, functional requirements (data frame forwarding, data frame filtering, network storm suppression, multicast, mirroring, multi-link aggregation, networking functions, management functions, communication security and others). 
Installation requirements The corresponding specifications include: installation location, outlet mode, and protection level.

The corresponding specifications for technical services include: Technical documents, information to be provided, and technical cooperation.

\section{B. Second-generation Smart Substation Switch Technical Specifications Change}

According to the use situation, the interface, performance, electromagnetic compatibility, environment, function and other requirements are standardized on the basis of industrial Ethernet switches, and how to test is specified. Main features: The choice of parameters (insulation performance, working conditions, product structure, electromagnetic compatibility) is significantly different from that of industrial switches, and the requirements of switches are higher. Due to the nature of power services, POE power supply, routing, Layer 3 multicast, and half duplex are not specified. Mode, clock interface and other unnecessary parts of the power system, thereby reducing product costs, simplifying the application of the equipment. technical parameters required for the power system such as delay, suppression, security, network storm, outlet mode, multiport mirroring, power supply Terminals and other mandatory requirements. Based on the first-generation switch technology, the default settings for the smart substation switch have been added as shown in Table I. Based on the first generation, the network management model was added to support the DL/T 860 specification and the Simple Network Time Protocol (SNMP) 2nd edition. The network management supports network topology discovery, device basic information, and working status identification. Log upload, port data volume statistics, and exception alarms. Support configuration file import and export, support Web page configuration to facilitate project debugging, have self-diagnostic function, and can output device self-test information.

TABLE I. SMART SUBSTATION SWITCH DEFAULT SETTINGS

\begin{tabular}{|c|c|c|}
\hline Switch function & $\begin{array}{l}\text { Factory } \\
\text { settings }\end{array}$ & Note \\
\hline Port speed limit & OFF & None \\
\hline $\begin{array}{l}\text { Virtual Local Area Network } \\
\text { (IEEE802.1Q VLAN) }\end{array}$ & ON & $\begin{array}{c}\text { The default } \\
\text { value is } 1\end{array}$ \\
\hline Absolute priority & $\mathrm{ON}$ & None \\
\hline Broadcast Storm Suppression & $\mathrm{ON}$ & $\begin{array}{l}\text { Suppression } \\
\text { ratio } 1 \%\end{array}$ \\
\hline Multicast storm suppression & OFF & None \\
\hline $\begin{array}{l}\text { Unknown unicast storm } \\
\text { suppression }\end{array}$ & $\mathrm{ON}$ & $\begin{array}{c}\text { Suppression } \\
\text { ratio } 10 \% \\
\end{array}$ \\
\hline Port mirroring & OFF & None \\
\hline $\begin{array}{l}\text { Multicast (static multicast, } \\
\text { GMRP and IGMP Snooping) }\end{array}$ & OFF & None \\
\hline $\begin{array}{c}\text { Precision Clock } \\
\text { Synchronization Protocol }\end{array}$ & OFF & None \\
\hline $\begin{array}{l}\text { Ring protection (RSTP, MSTP } \\
\text { etc.) }\end{array}$ & OFF & None \\
\hline $\begin{array}{c}\text { Web\Command-line } \\
\text { interface \Teletype network }\end{array}$ & ON & None \\
\hline Event record & $\mathrm{ON}$ & None \\
\hline IEEE802.1x port security & OFF & None \\
\hline $\begin{array}{c}\text { Simple Network Management } \\
\text { Protocol } \backslash \text { Remote Network } \\
\text { Monitoring }\end{array}$ & OFF & None \\
\hline
\end{tabular}

\section{Third Generation Intelligent Substation Switch Technical Specifications}

On the basis of the second generation, the device appearance and interfaces are added. For example, an indicator lamp is added to an array of over-limit warning lights. configuration file normative requirements and configuration files are automatically imported and exported [6]. information models and communication services such as regulations are perfect The self-describing capability uses the MMS mechanism to communicate with the monitoring host or network analysis device. The coherent information is sent directly through the MMS port, using Association, Release, and Abort services. Version management, device naming The device type, the number of fast communications interfaces, and the number of gigabit communications interfaces are composed of three parts, as shown in Figure I:

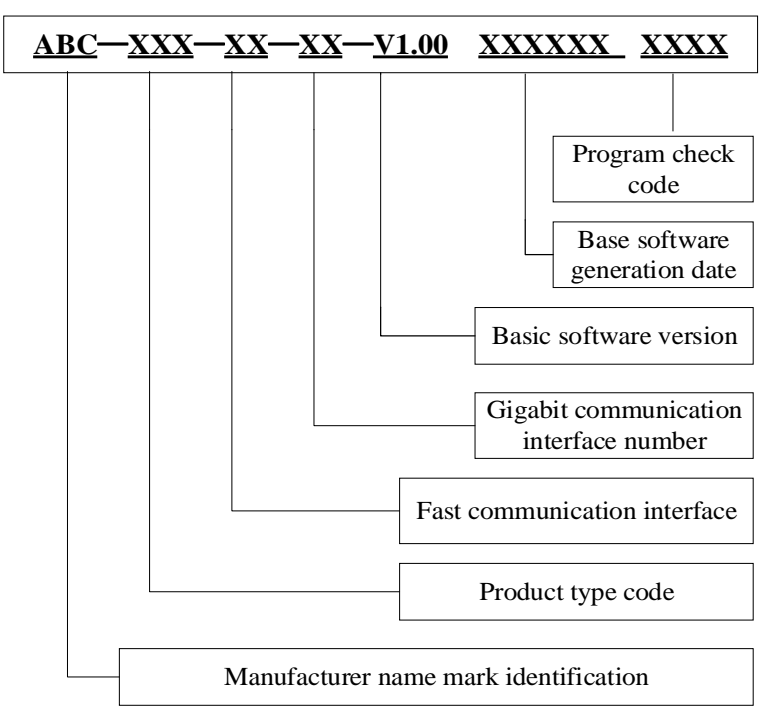

FIGURE I. DEVICE NAMING CONVENTIONS

Removed the requirements for SNMP. Added log requirements. For example, logs are divided into system logs and alarm logs. System logs record configuration and management information. Alarm logs record events such as restarts and alarms. Log requests are accurate to seconds. Logs are required at least. 1000 pieces of information can be stored and can be automatically overridden. network management, for example, you can set the initial IP address of the switch, login account and password. multiple mirrored ports, multicast traffic control, switch delay accumulation function, for example, according to the multicast MAC address automatically Identify different multicast groups and perform traffic control according to the set thresholds to avoid the adverse impact of abnormal multicast on the substation network. [7] The process layer switch should support the cumulative delay accumulation function of SV data frames. The switching delay cumulatively uses 4 reserved bytes in the SV data frame. The frame format is shown in Table II:

Time synchronization management, such as support for SNTP, PTP (Precision Time Protocol), NTP (Network Time Protocol, Network Time Protocol). Operational status monitoring and management, such as: self-test function, like 
communication abnormality, device power failure Information and other self-inspection information can be browsed and uploaded. the timekeeping method and time accuracy are modified. for example, the SNTP time synchronization accuracy rule should be less than $10 \mathrm{~ms}$, and the accurate network synchronization clock-to-clock protocol is supported. If the switch is used as a transparent clock, the The time synchronization accuracy error should be less than 200ns.

TABLE II. SMART SUBSTATION SV DATA FRAME EXCHANGE DELAY LABELING FORMAT

\begin{tabular}{|c|c|c|c|}
\hline \multicolumn{2}{|c|}{ SV data frame } & property & Note \\
\hline \multicolumn{2}{|c|}{ APDU } & - & \multirow{9}{*}{$\begin{array}{c}\text { Test: } \\
\text { maintenance } \\
\text { flag bit } \\
\text { OVF: overflow } \\
\text { flag bit } \\
\text { ART: exchange } \\
\text { delay } \\
\text { accumulated } \\
\text { value }\end{array}$} \\
\hline \multirow{4}{*}{$\begin{array}{l}\text { Reserved } \\
\text { field } \\
\text { (4 bytes) }\end{array}$} & $\operatorname{Bit}(0-23)$ & ART & \\
\hline & $\operatorname{Bit}(24-29)$ & Reserved & \\
\hline & $\operatorname{Bit}(30)$ & OVF & \\
\hline & $\operatorname{Bit}(31)$ & Test & \\
\hline \multicolumn{2}{|c|}{ PDU length(2 bytes) } & - & \\
\hline \multicolumn{2}{|c|}{ APPID(2 bytes) } & - & \\
\hline \multicolumn{2}{|c|}{ Ethernet type( 2 bytes) } & 0x88BA & \\
\hline \multicolumn{2}{|c|}{$\begin{array}{c}\text { Destination MAC / } \\
\text { Source MAC(12 bytes) }\end{array}$} & - & \\
\hline
\end{tabular}

\section{SMART Substation SWITCH PERFormance AnAlysis}

The status of the switch in the network is very important. Its performance is directly related to the security and stability of the network. The technology of intelligent substation network switches has been constantly improved. As the environment becomes more and more severe, its updates are also gradually accelerating and the performance has also been greatly improved. The performance indicators based on the latest smart station switch standard analysis are as follows:

- Total throughput: Refers to the switch's ability to forward packets.

- $\quad$ Address cache capability: The maximum number of MAC addresses that the switch can learn.

- $\quad$ Address learning rate: It refers to the switch learning rate of MAC address.

- $\quad$ Store-and-forward delay: It refers to the difference between the time when the first bit of the data frame occurs at the output port of the device and the arrival time of the last bit of data at the input port of the device.

- $\quad$ Delay jitter: Immediate delay changes.

- $\quad$ Frame loss rate: Refers to the value of the number of lost service frames compared to the total number of service frames sent in the interval t.

- Back-to-back frame: Refers to the number of data frames that can be transmitted at the maximum fixed length at the minimum frame interval.

- Header congestion: Refers to the cell behind the headof-line blocking (HOL) in the input buffer. Because of the FIFO principle, even if the output port of the cell is idle, data may be lost or delay may occur.

- Network storm suppression value: Generally considered to be the actual suppression result of the network storm.

- Multicast: Includes static multicast and GMRP (GARP Multicast Registration Protocol). Static multicast implements multicast packet filtering by configuring a static multicast address table of the switch. GMRP can receive other multicast data. The multicast registration information of the switch dynamically updates the local file and propagates the local multicast registration information to other switches.

- $\quad$ Time synchronization accuracy.

- $\quad$ Flow control threshold: The flow limit of the control.

- Accuracy of exchange delay.

- $\quad$ Power consumption: Switch power loss.

- Insulation performance: Refers to the switch's resistance to high voltage and the length of time it takes to break down.

- $\quad$ Damp heat: Refers to humidity and temperature.

- Mechanical performance: Refers to the performance of materials used in the switch.

- $\quad$ Electromagnetic compatibility (anti-interference and radio disturbance limit).

Switch performance indicators have a direct impact on device reliability, such as measurement and control, protection, etc. Therefore, the switch needs to meet the requirements of the process layer on EMC, mechanical performance and environment, and also on the functional requirements of the frame loss rate, throughput, group The performance indicators such as broadcast management and transmission delays are in line with the requirements of the process layer [8]. For the switch, the relationship between its performance and various indicators is not exactly the same, so the performance analysis of the switch cannot be compared from the surface alone, and it needs to be quantified, which may give a valuable reference. It is worth mentioning that because there are many indicators mentioned in the specification and the impact on performance is uneven, it is necessary to classify and purposefully select these indicators in order to achieve optimal results when performing performance analysis.

\section{Key Technology Discussion of Switch Function}

\section{A. Port Speed Limit}

LAN speed control and Internet traffic management are generally implemented through the port speed limit of the switch. When the LR (Load Runner) performance test method is used to test devices in a private network, the LR is based on the token bucket. Traffic measurement and control are performed. Token Buckets and Leaky Buckets are two 
commonly used current limiting algorithms [9]. The literature [10] analyzes how to implement traffic restrictions from the perspective of CAP (Content-aware processor). Literature [11] proposes a dynamic shared speed limit (DMS) algorithm. The shared speed limit channel is used simultaneously for multiple streams. It is applicable to limited hardware resources. The speed limit channel is determined, and the number of streams requiring rate limiting is more than the rate limiting channel. Some researchers implement flow control based on the flow control method of the target MAC address [12], and combine the edge port input flow restriction and static multicast management to control the network traffic at the process level. The effect is also obvious [13].

\section{B. Virtual Local Area Network (IEEE802.1Q VLAN)}

In smart substations, switch VLANs are commonly used to implement network packet filtering. Therefore, Li Zhijian et al. proposed a method of VLAN ID allocation and distribution, which makes the VLAN ID readable and beneficial to engineering applications [14]. The VLAN division modes are port-based VLAN, MAC address-based VLAN, route-based VLAN, and policy-based VLAN. Commonly there are voltagelevel, function-based process-level network VLAN divisions. Ding Jinjin et al. according to transmission protocols and VLAN technologies, refer to process-level network VLAN division methods based on voltage level and IED [15], and literature [16] discusses The optimization and configuration of PVID, VID, and IP are based on the differences between devices in different voltage levels in the station to implement reasonable VLAN division.

\section{Absolute Priority}

A major feature of smart substations is the use of optical fibers instead of traditional cables. In the case of switches using Fibre Channel, a three-level priority strategy is designed. The VOQ (Virtual Output Queue) mechanism and Crossbar distribution are described for the input ports. The important technologies such as the scheduling of the structured structure and the control of the output ports enable high-priority data to be scheduled and output as quickly as possible [17].

\section{Storm Suppression}

In the early stage of the construction of smart substations, the switch adopts advanced technologies and strengthens management during the later period of maintenance to reduce the occurrence of network storms. At present, GMRP is generally used, hardware Hash, VLAN filtering, packet typebased filtering, and feature filtering are used at the end of the device [18]. Field-programmable gate array (FPGA) or the driver layer of the CPU can also be used to implement message type filtering. At this time, the filtering is completed by the CPU, and the requirements of the IED are closely related. The storm suppression is in place. Table III compares current storm suppression technology for smart substation switches [19].
TABLE III. SWITCH STORM SUPPRESSION TECHNOLOGY

\begin{tabular}{|c|c|c|}
\hline $\begin{array}{c}\text { Technical } \\
\text { name }\end{array}$ & $\begin{array}{c}\text { Applicable } \\
\text { links }\end{array}$ & Features \\
\hline GMRP & $\begin{array}{l}\text { Process } \\
\text { Level } \\
\text { Network }\end{array}$ & $\begin{array}{l}\text { Provides a limited multicast } \\
\text { flooding function to ensure } \\
\text { consistent multicast information on } \\
\text { GMRP-enabled devices in the same } \\
\text { switching network }\end{array}$ \\
\hline $\begin{array}{l}\text { Broadcast } \\
\text { filtering }\end{array}$ & $\begin{array}{l}\text { bay level } \\
\text { IED }\end{array}$ & $\begin{array}{c}\text { Can solve IED bay layer network } \\
\text { communication interruption and } \\
\text { device restart failure in broadcast } \\
\text { storm }\end{array}$ \\
\hline $\begin{array}{c}\text { Hardware } \\
\text { hash filtering }\end{array}$ & $\begin{array}{c}\text { Process } \\
\text { Level IED }\end{array}$ & $\begin{array}{l}\text { For the hardware architecture of the } \\
\text { MAC directly connected to the } \\
\text { CPU, } \\
\text { can reduce the CPU's excess load }\end{array}$ \\
\hline $\begin{array}{c}\text { Static } \\
\text { multicast }\end{array}$ & $\begin{array}{l}\text { Process } \\
\text { Level } \\
\text { switch }\end{array}$ & $\begin{array}{l}\text { Manually configure the multicast } \\
\text { table of the switch to suppress the } \\
\text { broadcast packets }\end{array}$ \\
\hline VLAN & $\begin{array}{l}\text { Process } \\
\text { Level } \\
\text { switch }\end{array}$ & $\begin{array}{l}\text { Limit the broadcast domain, the } \\
\text { virtual work group structure is more } \\
\text { flexible }\end{array}$ \\
\hline $\begin{array}{l}\text { Spanning } \\
\text { Tree }\end{array}$ & $\begin{array}{l}\text { Process } \\
\text { Level, } \\
\text { bay level } \\
\text { Network }\end{array}$ & $\begin{array}{c}\text { Can effectively prevent the } \\
\text { loopback of the LAN in the LAN } \\
\text { and solve the "broadcast storm" } \\
\text { generated by the loop Ethernet } \\
\text { network }\end{array}$ \\
\hline $\begin{array}{l}\text { IEC62439 } \\
\text { redundancy }\end{array}$ & $\begin{array}{l}\text { Process } \\
\text { Level, } \\
\text { bay level } \\
\text { Network }\end{array}$ & $\begin{array}{l}\text { It is more convenient for different } \\
\text { manufacturers to access the same } \\
\text { network }\end{array}$ \\
\hline
\end{tabular}

\section{a) Broadcast storm suppression:}

When the network is flooded with broadcast signals but cannot be cleared in time, the network bandwidth may be contended by these broadcast signals, making it impossible for other data to be properly transmitted and received, which may cause network congestion.

\section{b) Multicast storm suppression:}

Sending signals through multicast improves the efficiency of data transmission and reduces the probability of congestion in the backbone network. However, there may be continuous multicasting of malicious software to cause multicast storms. At this time, it needs to be suppressed to prevent network failures.

\section{c) Unknown unicast storm suppression:}

When the switch starts up, the MAC address table is empty. At this time, host A sends a frame of data to host B. When the switch receives this frame, it queries the source address (for host A) and adds it to the host. In the MAC address table, the switch may not know which port the host $\mathrm{B}$ is (because the MAC address of the host B is not in the MAC address table), and this frame is an unknown unicast frame. The switch floods the frame. At this point, we need to take steps to suppress this phenomenon.

\section{E. Port Mirroring}

The problems of port mirroring include overloaded mirror ports, missing data sources, and low traffic on some mirrored ports. The general processing methods include filtering, aggregation, and distribution. Preprocessing is performed between the original data and the back-end analysis device to 
ensure the original data source. Data volume, delivery methods, and data content have been optimized.

\section{F. Multicast (Static Multicast, GMRP, and IGMP Snooping)}

Multicast refers to the form of point-to-multipoint connection between the sender and the receiver. Static multicast is implemented through static configuration.

GMRP is a kind of GARP, which usually provides the management function of Layer 2 multicast. It provides a dynamic general framework that enables multicast information in the manner of publishing subscriptions to be queried, registered, and unregistered in Ethernet [20]. The process layer network data filtering technology mainly uses GMRP and VLAN, but these two methods do not conflict. In practice, one or the other may be used as required.

The Internet Group Management Protocol (IGMP) is a network layer protocol, and the switch belongs to a Layer 2 device. IGMP Snooping is a Layer 2 multicast protocol and is a multicast constraining mechanism that operates on data link layer devices. Manage and control multicast groups to avoid the switch to redundantly forward multicast data to lose bandwidth. The basic idea is to listen to IGMP report and leave messages to maintain Layer 2 multicast tables and manage multicast on all ports of the switch. The group member thus determines the data forwarding of the member object [21].

\section{G. Precision Clock Synchronization Protocol (PTP)}

As a universal time synchronization protocol, PTP calculates the master-slave time offset (Offset) and network delay (Delay) of each clock device in the PTP network system, corrects the deviation and compensates the delay, thereby realizing time synchronization and conforming to the networked distributed system. The demand [22]. End-to-end transparent clock (E2E) and point-to-point transparent clock (P2P) can calculate the delay of PTP packets in the network switching equipment.

\section{H. Ring Protection}

The spanning tree protocols generally include a rapid spanning tree protocol (RSTP), a multiple spanning tree protocol (MSTP), and a spanning tree protocol (STP). The literature [23] holds that the main idea of STP is to construct a switching network into a logically tree-like network so as to avoid loops in the network. RSTP improves the convergence speed with respect to STP, and MSTP applies the RSTP algorithm to MST. In Multiple Spanning Tree (Multi Spanning Tree), multiple spanning trees are built for the entire switching network, and multiple VLANs can be associated with one spanning tree so that they are independent of each other and have their own topology. Make VLAN switching networks fast and load balanced.

\section{Web\Command-line Interfacel Teletype Network}

CLI (command-line interface), Telnet (teletype network), and Web are three types of network management methods. [24] pointed out that in CLI-based management, a user enters a CLI command and the CLI proxy verifies it, and takes a series of actions based on user input including: access permission control, identity authentication, action execution, CLI command analysis, and validity Sex check, call request to system or protocol module.

The WEB-based management mechanism is very similar to the other two agents. The embedded server in the switch receives and sends data with management information. Although these three management methods have different front ends, the back ends are the same. It can be seen from Figure II that they all issue requests to the protocol modules or systems to perform operations.

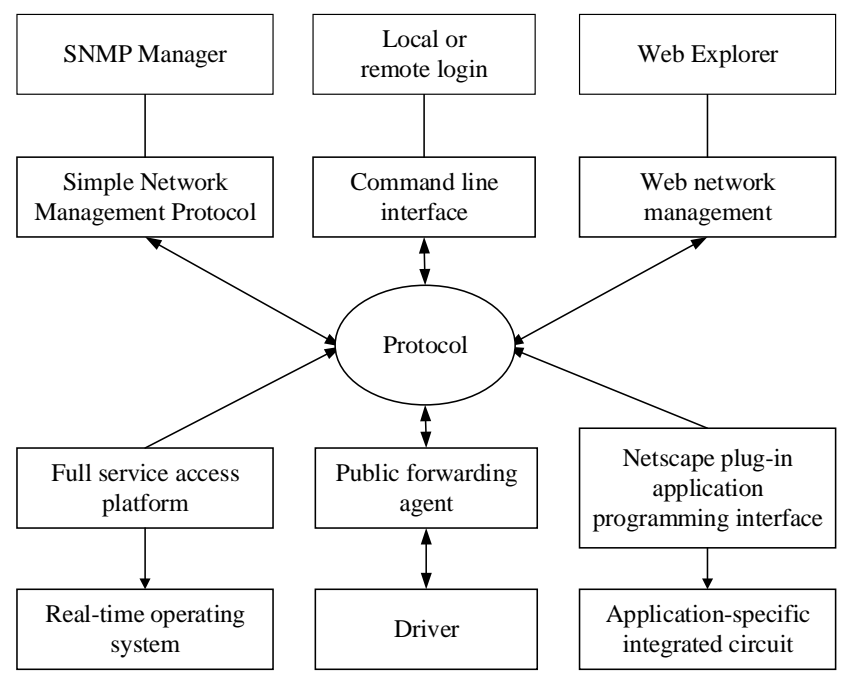

FIGURE II. SWITCH ARCHITECTURE AND MANAGEMENT

\section{J. Event Record}

The event record can provide help for fault analysis and fault prevention. The fault or event occurred while the switch is running is recorded in the log alarm.

\section{K. IEEE802.1x Port Security}

Both 802.lx authentication based on the access layer and 802.1x authentication based on the convergence layer are used to ensure port security. [25] proposes to improve the frame structure to solve the man-in-the-middle attacks and DDoS (incompletely solved by the currently designed protocols). Distributed Denial of Service denial of service) attacks and other issues.

\section{Simple Network Management Protocol $\backslash$ Remote Network Monitoring}

SNMP is used as a common communication protocol to collect management information from the devices in the network. RMON (Remote Network Monitoring) is one of the widely used network management standards. It is mainly used to monitor a network segment and Data traffic in the entire network adopts RMON technology to maintain network fault and performance management. By setting statistics related to the use of statistics interfaces at the physical layer and setting related limits for alarms, it is possible to solve the limitation that SNMP cannot perform historical analysis of daily traffic. Reference [26] discusses the simulation of a large-scale network device by constructing an SNMP management-based 
system. The use of this tool requires 10000 network devices on the server, and the emulator can easily implement the MIB data of real devices. The interaction aspects of the network layer communication and the data are $100 \%$ emulated and in response to a large-scale request, the efficiency must not be lower than that of a real hardware device. For large networks, the SNMPv1 query mechanism also causes a large number of management messages to occupy too many network resources. RMON is the most important enhancement to SNMP. By extending the basic MIB and management functions, you can monitor the network and reduce management. The traffic between the station and the agent and the data collected through the agent reduce the burden on the management station.

\section{CONCLUSION}

This article first compares and summarizes the technical specifications and Changes in standards of switches in smart substations and the technical characteristics of each stage. Secondly, the latest performance requirements of the switch are analyzed. Then from the perspective of function realization, we discussed the key technologies that support the development of switches. Switch VLAN auto-configuration, storm suppression, and clock synchronization are hot research points at present. Some research results have been achieved in the field of smart substation switches. However, there are still rigorous details, uncontrolled network risks, less port security research, and automation. Raising such issues can be a follow-up research point. It is believed that with the in-depth development of the future, smart substation network switch technology research will build a more stable and efficient smart grid.

\section{ACKNOWLEDGMENT}

This research was sponsored by the Science and Technology Project Headquarters of State Grid Corporation of China (No. 52199916024F).

\section{REFERENCES}

[1] Y. Qiu, X. Hu, G. Ling, Q. Luo, and Y. Zhao, "Research on State Grid's technical specification system of relay protection in smart substation," 20rd ed, vol. 45, Power System Protection and Control, 2017, pp. 7-13.

[2] X. Huang, "Development Overview and Technical Verification of Smart Substation Network Switch,” 5rd ed, vol. 13, Electric Power Information and Communication Technology, 2015, pp. 6-11.

[3] State Grid Corporation of China. Smart Substation Network Switch Specifications: Q/GDW 429-2010[S]. Beijing: China Electric Power Press, 2010.

[4] State Grid Corporation of China. Smart Substation Network Switch Specifications: Q/GDW 1429-2012[S]. Beijing: China Electric Power Press, 2012.

[5] State Grid Corporation of China. Smart Substation Network Switch Specifications: Q/GDW 2429-2014[S]. Beijing: China Electric Power Press, 2014.

[6] Z. He, Y. Zheng, X. Li, X. Liao, and Y. Liu, "Visualization research on secondary equipments simulation training system for smart substation," 6rd ed, vol. 44, Power System Protection and Control, 2016, pp. 111-116.

[7] J. Cai, Y. Zheng, Z. Zhou, et al, “A survey of research on secondary device condition monitoring in smart substation," 6rd ed, vol. 44, Power System Protection and Control, 2016, pp. 148-154.

[8] G. Yang, Z. Wang, W. Wang, M. Liu, and X. Zhou, "Intelligent Substation Process Level Switch Key Technology Discussion,” vol.1, Electrical Engineering, 2012, pp. 51-55.
[9] W. Wei, X. Ren, and H. Yu, "Research on rate-limit technology of IP network port,” vol.3, Information Technology, 2016, pp.136-138.

[10] X. Zhou, G. Yang. Z. Yuan, W. Wang, and M. Liu, "Rate Limiting Technology of Switch and Its Application in Smart Substation,” 18rd ed, vol. 38, Automation of Electric Power Systems, 2014, pp. 114-119.

[11] J. Yang, C. Xu, Z. Gong, C. Hu, and X. Guan, "A Mechanism of Dynamic Meter Sharing on OpenFlow Switch,” 6rd ed, vol. 39, Chinese Journal of Computers, 2016, pp. 1224-1236.

[12] G. Yang, H. Lv, Z. Yuan, J. Liu, and C. Zheng, "Research and realization of intelligent substation process level network flow control and synchronization method,” 11rd ed, vol. 43, Power System Protection and Control, 2015, pp. 70-74.

[13] M. Liu, X. Zhao, M. Si, et al, "Research and application of process level network flow management in smart substation,” 23rd ed, vol. 40, Power System Protection and Control, 2012, pp. 87-92.

[14] Z. Li, X. Jiang, G. Yao, R. Zhao, and L. Bai, “Application of Virtual Local Area Network in Process Layer Network of Intelligent Substation,” s1rd ed, vol. 45, Electrotechnical Application, 2015, pp. 373-377.

[15] J. Ding, B. Gao, N. Liu, and L. Guo, "Research on network structure and VLAN division plan for smart substation,” 3rd ed, vol. 36, Journal of Hefei University of Technology(Natural Science), 2013, pp. 287-291.

[16] T. Ding, Y. Ling, and M. Zhao, "Research of the virtual local area network in smart substation," 1rd ed, vol. 40, Power System Protection and Control, 2012, pp. 115-119.

[17] D. Li and Y. Chang, "Research and Realization of Priority Technology Based on FC Switch," 12rd ed, vol. 34, Measurement \& Control Technology, 2015, pp. 100-102.

[18] T. Huang, P. Liu, G. Xin, P. Wang, and Y. Wang, "Analysis and Treatment of Process-Level Network Storm in Smart Substation,” 11rd ed, vol. 47, Power System Protection and Control, 2014, pp. 112-115.

[19] Z. Wang, Z. Du, Z. Dong, et al, "Study of Intelligent Substation Network Storm Suppression Technology,” 2rd ed, vol. 11, Journal of Electrical Engineering, 2016, pp. 40-46.

[20] G. Li, "Digital substation networking technologies," 2rd ed, vol. 33, Electric Power Automation Equipment, 2013, pp. 142-146.

[21] H. Zhang and X. Zheng, "Design and practice of process level network in substation based on GMRP," vol. 7, Computer Engineering \& Design, 2015, pp. 1681-1685.

[22] Z. Huang, W. Chen, and X. Wang, “Application of IEEE1588 protocol on industrial Ethernet switch,” 23rd ed, vol. 35, Modern Electronic Technique, 2012, pp. 90-93.

[23] S. Qi, "Design and Implementation of MSTP Based on LINUX," University of Electronic Science and Technology of China, 2012

[24] G. Zeng, "Research and Implementation of Switch Network Management System," National University of Defense Technology, 2008.

[25] B. Wan, H. Gan, and X. Dong, "802.1x port authentication defects and its improvement," 1rd ed, vol. 41, Study on Optical Communications, 2015, pp. 23-25.

[26] G. Chen, "Design and Implementation of Large-Scale Network Device Simulation System Based on SNMP,” Xiamen University, 2016. 